\title{
O DESAFIO DA FORMAÇÃO DO EDUCADOR NA PERSPECTIVA DO MARXISMO
}

\author{
Paulino José Orso ${ }^{1}$
}

\section{RESUMO:}

Como o próprio título indica, este artigo trata da formação do educador na perspectiva marxista, que se significa compreender o educador como inserido na sociedade, fazendo parte da totalidade, sujeito às contradições e antagonismos sociais, próprios da realidade em que se encontra inserido. Apesar de se ocupar de um tema aparentemente batido, procura trazer para a discussão elementos que ainda não foram suficientemente considerados acerca da temática em questão. Para isso, tomando um significativo distanciamento metodológico, aos poucos, procura ir desvelando e fugindo das aparências, buscando a essência da problemática da formação de professores. A temática proposta para esta discussão, por um lado, remete para a problemática da formação do professor, para o como e de que forma o educador está sendo formado e, por outro, para o como e de que forma deve ser preparado para educar.

Palavras-chave: Formação do educador, Marxismo e Educação, Educação e Sociedade

\section{THE CHALLENGE OF EDUCATOR TRAINING IN VIEW OF MARXISM}

\section{ABSTRACT:}

As the title indicates, this article deals with the preparation of educators in the Marxist perspective, that means understanding the educator as within society as part of the whole subject to the contradictions and social antagonisms, fit the reality in which it is inserted. Although they occupy a theme apparently beaten, seeks to bring to the discussion items that have not been addressed sufficiently on the subject in question. For this, taking a significant methodological gap, gradually unveiling seeks to go and walking away from appearances, seeking the essence of the problem of teacher training. The proposed theme for this discussion, on the one hand, refers to the problem of teacher training, and as to how the teacher is being formed and, secondly, to how and in what way should be prepared to educate.

Keywords: Teacher education, Marxism and Education, Education and Society

Antes, porém, de entrar propriamente na questão proposta para a discussão neste artigo, gostaria de tecer algumas observações.

Gostaria de dizer que:

1) Quando se trata de falar da formação do educador é um grande desafio, pois, já se têm feito muitas discussões, fóruns, seminários, colóquios e eventos sobre esta temática. Além disso, também foram escritos muitos artigos e livros sobre ela. É bem provável que a formação do educador juntamente com as políticas educacionais, estejam entre as temáticas mais debatidas na área da educação. Claro que não é o caso de dizer o que já foi dito sobre isso. Então, o que, como e de que forma abordar esta temática. O que falar e escrever de novo, sem cair nas questões novidadeiras ou nas saídas de tipo pós-modernas, nas ditas propostas neoliberais, na defesa da pedagogia das competências ou do aprender ser, do aprender fazer? Quando nos referimos em algo novo, porém, gostaria de destacar que não significa que pretendemos inventar algo que ninguém tenha dito nada sobre, mas sim, recolocar o problema à luz da história, do que já foi dito e escrito, bem como, a partir do problema evidenciado pela realidade e pela sociedade no atual momento. Mesmo 
porque não é possível se pensar e produzir algo totalmente novo, sem que o velho, o existente não possibilite isso.

2) Não vamos enfrentar o problema todo de uma vez. Um problema ou um desafio não se resolve numa penada. Assim como o novelo de lã não se desfia de uma só vez, vamos resolver essa questão aos poucos, como se fossemos desfiando um novelo.

3) Ainda que a temática se refira a educador e não professor, para os fins deste texto, nos damos o direito de não fazer tal distinção e tratar como se fossem a mesma coisa. Vamos tratá-los como sinônimos. Portanto, de acordo com a ocasião nos referiremos a educador e em outros a professor de forma indistinta.

4) Quando estamos muito próximos ou envolvidos com alguma questão, da mesma forma que quando ficamos ou estamos muito distantes delas, corremos o risco de não as compreendermos bem. Ambas as atitudes são prejudiciais à análise e ao entendimento das questões. Então, ao abordar a questão da formação de professores procuraremos, ao mesmo tempo, não mergulharmos e ficarmos afixionados nela, como também não nos distanciarmos demasiadamente. Procuramos encontrar uma justa medida de aproximação e afastamento para compreendê-la bem, sem ficarmos cegos.

Depois de ter feito estas observações, vamos à questão. A temática proposta para esta discussão, por um lado, remete para a problemática da formação do professor, para o como e de que forma o educador está sendo formado e, por outro, para o como e de que forma deve ser preparado para educar.

Procurando ser coerente com o método marxiano, partimos da aparência para mergulhar na essência, para depois retornar à aparência, resignificando-a. Isso significa que partiremos do aqui e agora, de como a formação do educador é tratada e compreendida na atualidade ou a partir da modernidade, para depois nos debruçarmos sobre os determinantes históricos que tornaram possível esta realidade e compreender como foi produzida de tal modo, para, finalmente retornarmos à atualidade, resignificando-a.

Se observarmos um pouco à nossa volta, veremos que os investimentos na educação são precários, sobretudo nos cursos de licenciaturas; as escolas encontram-se sucateadas, funcionando com um mínimo de materiais, com bibliotecas carentes, com salas de aula apinhadas de alunos trabalhadores, tendo que conjugar os estudos com o trabalho, que em muitos casos também é bastante precário, recebendo baixos salários; os professores são mal formados, também recebendo baixos salários, tendo que realizar uma dupla ou tripla jornada de trabalho, sem condições de adquirir livros, sem poder estudar, pesquisar, se atualizar, planejar as atividades, restando apenas como referência para o trabalho, a experiência adquirida ao longo dos anos, a atividade prática desprovida de reflexão sobre o porquê, a importância, o significado, as implicações e as consequências do trabalho que realiza. Vemos professores realizando atividades escolares isoladas, individualizadas, desprovidas e desvinculadas de um Projeto Político Pedagógico agregador, que articule e integre o conjunto das ações desenvolvidas na escola ${ }^{2}$; vemos a ausência de uma reflexão sobre a concepção de homem, de mundo, de educação e de sociedade.

Mas, o que é que isto tem a ver com a formação de professores? O artigo não trata disso? Sim. O fato é que, ao invés de, como dissemos, ir diretamente á questão, optamos por fazer um caminho diferente que parta da prática, ou seja, procuramos a partir das condições concretas depreender qual a importância e o tipo de formação que é dispensada aos professores nesta sociedade. Então, a partir dos elementos elencados acima, pode-se dizer de chofre que, quando falamos da formação de professores não temos muito o que comemorar.

Veja-se que quando falamos da questão da formação de professores, portanto, não se trata de uma questão meramente teórica, mas sim de uma questão prática. Ou seja, a 
realidade concreta da escola, as condições de ensino e aprendizagem, revelam o tipo de preocupação e a importância que se atribui à formação do educador e à educação. Aqui também se coloca a questão relação entre teoria e prática, ou então, do que vem antes: a teoria ou a prática, ou ainda, da indissociabilidade entre teoria e prática. Ou ainda, o fato de que não é possível dissociar a formação de professores da sociedade, das condições e do modo de organização e funcionamento da sociedade.

Entretanto, este problema não se resolve no plano do pensamento, mas sim da prática. Significa que o pensamento, a reflexão, a teoria não são importantes, não são necessários? Não. Significa apenas que, em última instância, a prova que revela, que manifesta se de fato o problema foi ou não resolvido, não está no pensamento e na teoria, mas sim na realidade concreta, na prática social.

Se por um lado, o pensamento, a reflexão, a teoria não são suficientes para resolver os problemas, por outro, não se pode desprezá-las, nem dispensá-las. Ao contrário, constituem-se em instrumentos e meios necessários e indispensáveis à solução dos problemas.

Então, o que vem antes, a teoria ou a prática? À primeira vista, parece que o que vem primeiro é a teoria e depois a prática. Pois, se o pensamento e a teoria são meios pelos quais podemos antecipar a solução no plano do pensamento e depois agir, realizar e transformar a realidade, então, aparentemente, o pensamento e a teoria parecem como se tivessem primazia.

Isto, porém, como dissemos, só aparentemente, pois, se o problema está ou aparece como tal no ou para o pensamento é porque já está na realidade, ou seja, está na prática e, por isso, também aparece assim no pensamento. Dizendo de outro modo, se a formação de professores aparece como problema a ser debatido e discutido no plano do pensamento, das ideias, das teorias é porque já se revela como problema na prática.

Assim, pode-se concluir que o que vem primeiro é a prática e depois a teoria. Porém, se observarmos, frequentemente nos referimos à relação teoria-prática e não prática-teoria. Neste sentido, o fato de geralmente falarmos da relação teoria-prática, nesta sequência e não o inverso, da prática-teoria, denota uma concepção de mundo; revela a influência e até mesmo a tendência que temos de adotar a perspectiva idealista. Contudo, o caminho correto da práxis social vai da prática para a teoria e desta para a prática e assim sucessivamente. Como diria Marx, este é o modo efetivo como se processa a gênese do pensamento ${ }^{3}$.

Esta concepção, por exemplo, opõe-se ao famoso princípio racionalista cartesiano, o princípio de René Descartes: "Penso, logo existo", como se o homem fosse produto de si mesmo, ou melhor, de seu próprio pensamento; como se o homem fosse posto ou a realidade fosse posta pelo pensamento - aqui o primado está na razão. Opõe-se também à concepção bíblica ou criacionista, para quem, o Pensamento cria a realidade, sintetizado na

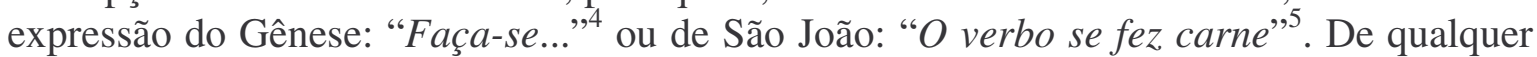
modo, significa que a realidade é produto da ideias, do pensamento, da teoria e não o inverso. Neste caso, significa que as ideias põem e criam a realidade a partir do nada, do pensamento puro.

Então, como vivemos numa sociedade e numa cultura que historicamente foram e ainda são marcadas pela religiosidade e, numa sociedade burguesa e de classes, cuja adoção da perspectiva idealista, que acredita resolver os problemas no plano do pensamento e das ideias, deixando intacta a realidade concreta, é muito conveniente à reprodução da sociedade vigente, também temos a tendência de supor que as ideias, que a teoria vem antes, dando vazão e enfatizando o próprio idealismo em oposição ao materialismo, fazendo do pensamento o motor da realidade ${ }^{6}$. 
Marx, referindo-se ao idealismo Hegeliano, afirma que

Hegel caiu na ilusão de conceber o real como resultado do pensamento que se sintetiza em si, se aprofunda em si, e se move por si mesmo; enquanto que o método que consiste em elevar-se do abstrato ao concreto não é senão a maneira de proceder do pensamento para se apropriar do concreto, para reproduzi-lo como concreto pensado. Mas este não é de modo nenhum o processo da gênese do próprio concreto ${ }^{7}$.

Ou seja, a realidade não é produto das idéias, nem o pensamento gera a realidade. Ao contrário, por um lado, o pensamento é que é produto da realidade e, enquanto tal, transforma-se em um instrumento, em um meio de apropriação e de ação sobre ela.

Posto isso, poderíamos pressupor que a realidade se desenvolve linearmente, isto é, se a prática precede as idéias, teríamos um movimento que vai da prática para o pensamento e deste para a prática e novamente para o pensamento, numa infindável sucessão de formas, previamente determinadas, unilateral e linearmente. Entretanto, a realidade não é uma sucessão de prática-teoria-prática-teoria e assim por diante. Muito menos o contrário. Temos sim, um movimento que se constitui numa totalidade dialética e contraditória que integra teoria e prática simultaneamente, num movimento indissolúvel.

Em se tratando, porém, do movimento teoria e prática ${ }^{8}$, pode-se afirmar que não há prática sem teoria e nem teoria sem prática. Uma pressupõe a outra. Num determinado ponto do processo de desenvolvimento da matéria, a cada realidade equivale uma teoria e a cada teoria uma prática. Ou ainda, cada modo de produção e organização da sociedade suscita uma determinada teoria ou uma representação de ideias que a legitimam e justificam, assim como, cada representação ou teoria pressupõe uma prática equivalente. Há uma unidade contraditória em cada realidade. Dito de outro modo, nem as idéias pairam no ar, existem por si e são produtos de si mesmas, nem a prática existe desprovida de uma teoria correspondente.

Porém, se por um lado, elas se pressupõem, por outro não há um determinismo, que é a impossibilidade de descolamento de uma em relação à outra. Assim, se poderia dizer que o tipo de formação de professores de cada época corresponde à sociedade da época.

Agora, então, parece que entramos num círculo vicioso e sem saída e, ao invés de um desenvolvimento linear, teríamos um desenvolvimento natural e espontâneo. Porém, como não temos um determinismo, a possibilidade de romper com o processo de mudança natural e superar a realidade, está na teoria e no pensamento que, partindo da realidade e da prática existente, pode se debruçar sobre ela, apropriar-se, refletir, planejar, "manipular" e antecipar os resultados no plano do pensamento e possibilitar uma ação sobre a problemática existente tendo em vista sua superação.

Assim voltamos à questão da formação do educador. A questão proposta remete, como vimos, à formação do educador, de como e de que forma ela é feita. Se, porém, ela estivesse à altura das exigências e necessidades da época, estaríamos aqui discutindo e colocando em questão a formação do educador? Ou seja, sendo coerentes com nosso princípio, temos que admitir que só estamos discutindo e teorizando sobre esta temática, porque antes o problema aparece e está na prática, na forma como o professor está sendo formado e, portanto, nas implicações, nas consequências dessa formação e, assim, exigindo que se pense as possíveis tendências que está a indicar, bem como, que se busque possíveis alternativas a ela. Ou ainda, é o fato de a formação do professor estar se revelando como um problema pela forma como ela é feita, que estamos discutindo, pensando, problematizando e teorizando sobre como é e como deve ser, sobre como transformá-la. 
Para além de todo o discurso sobre a importância e a prioridade da educação, vemos que predomina um descaso muito grande em relação à escola. Revela que efetivamente não é considerada como importante, necessária e prioritária para a sociedade. Aliás, creio que se dependesse dos políticos, por exemplo, é bem provável que seria extinta. Enfim, como se criou um discurso e uma espécie de consenso sobre sua necessidade, trata-se de fazê-la, porém, de forma barata e esvaziá-la em seus conteúdos e sua forma, para que não crie nenhum problema. Isto revela o desprezo o da escola e o descaso da política.

Contudo, o problema não é só o fato de que os conhecimentos, os bens espirituais, sejam distribuídos em conta gotas, mas sim que os produtos do conhecimento, os bens materiais, produzidos em decorrência do acúmulo de conhecimentos realizados ao longo da história, também são extremamente pobres e limitados às mínimas condições de sobrevivência dos trabalhadores.

Assim, enchem-se as salas de aula com alunos, mas se atribui às escolas um infindável conjunto de responsabilidades que acabam esvaziando sua finalidade principal, que é ser verdadeiros centros de produção, apropriação e socialização dos conhecimentos científicos e da cultura historicamente acumulada. Diante destas condições, na escola acaba por prevalecer o espontaneísmo, "o ir fazendo", o praticismo.

$\mathrm{E}$, para coroar tudo isso, para resolver o que entendem como sendo os problemas da educação ditas pós-moderna e neoliberal, apresentam como saída a pedagogia das competências, isto é, querem um professor à moda tecnicista, que tenha habilidade, seja competente, que saiba fazer, noutras palavras, que dê resultados. Partindo de uma concepção mercadológica, aliás, adequada à sociedade capitalista em que vivemos, que transforma tudo em mercadoria, não se poderia esperar outra coisa, senão que a educação também fosse pensada e submetida à mesma lógica do mercado, produtivista e de resultados.

Como diz Marx,

Nenhuma formação social desaparece antes que se desenvolvam todas as forças produtivas que ela contém, e jamais aparecem relações de produção novas e mais altas antes de amadurecerem no seio da própria sociedade antiga as condições materiais para a sua existência. Por isso, a humanidade se propõe sempre apenas os objetivos que pode alcançar, pois, bem vistas as coisas, vemos sempre que esses objetivos só brotam quando já existem ou, pelo menos, estão em gestação as condições materiais para a sua realização ${ }^{9}$.

Trazendo esta questão para a temática que estamos nos ocupando, significa que as transformações pelas quais a sociedade foi passando, primeiro produziram a necessidade da formação de professores, depois a colocaram em questão. Então, apresenta-se um problema prático e ao mesmo teórico. Prático, porque a realidade está apresentando os limites da atual formação de professores, e teórico, porque coloca o desafio para o pensamento e para teoria em compreender esta realidade e encontrar a solução do problema. Pois, caso continuemos a pensar, agir e formar professores do mesmo modo, teremos mais do mesmo.

Então, temos necessidade de pensar como está ocorrendo, para "manipular" a realidade no plano do pensamento e agir sobre ela, transformando-a. Se, como diz Marx, nenhuma filosofia pode ser superada sem que a materialidade assim o exija, sem que se 
crie as condições para tal, então, pode-se afirmar que o problema está posto e espera pela contribuição do pensamento e da teoria para superá-la.

$\mathrm{Na}$ perspectiva do liberalismo e do positivismo, fala-se que a formação do professor é um problema porque o problema está no professor: que está despreparado, que é incompetente, mal formado e assim por diante. Ou seja, primeiro desloca-se e isola-se o professor do conjunto das relações, como se existisse por si, separado e independente da totalidade social; como se as condições nas quais se encontra dependessem apenas dele e fossem de sua exclusiva responsabilidade. Depois se atribui a ele a responsabilidade por resolver praticamente todos os problemas sociais. Se exige, por exemplo, que seja uma espécie de pai/mãe, de psicólogo, que seja responsável pelo desenvolvimento social, que controle o vale disso, o vale daquilo, da quilo outro, que solucione o problema da miséria social, que resolva as políticas de assistência, que preste assistência à saúde dos alunos, que faça promoção disso e daquilo, que comemore o dia disso e daquilo, enfim, que até mesmo ensine um pouco. E, como não consegue dar conta e nem pode fazer isso tudo, como não consegue resolver todas as responsabilidades atribuídas ele, que não são poucas, então se conclui que é ele o responsável pelo fato de a educação encontrar-se da forma como está. Mas, como dar conta de tanta responsabilidade e de tantas exigências sendo apenas um elemento do meio e não a totalidade social? Qual o espaço que resta para se ocupar do conhecimento científico, da apropriação da cultura historicamente acumulada, da pesquisa, do estudo e do planejamento das atividades? Qual deve ser o papel do professor? Quais são seus limites e possibilidades?

Estas são questões que devem ser consideradas quando se pensa na formação do professor; quando se pensa em: para que, como, de que forma, por que meios, para que e como deve ser formado o educador.

Recorrendo à história da educação brasileira, numa rápida pincelada, vemos que a preocupação com a formação de professores, não é algo tão recente e que passou por diferentes enfoques e sofreu influências diversas. Nas últimas décadas, porém, tem sido um tema constante nos debates travados, sobretudo, nas universidades, nos espaços acadêmicos, nos curso de formação, quer sejam eles, de formação inicial ou continuada, presencial ou à distância.

A formação de professores no Brasil, já experimentou diferentes métodos e enfoques, sejam eles dos Jesuítas com sua Ratio Studiorum, ou de Lancaster e de Bell com o método intuitivo ou dos derivados dos ideários positivistas e liberais, em suas diferentes versões. Todavia, até o momento ainda não tivemos uma proposta genuinamente nacional, com exceção da pedagogia de Paulo Freire, que acabou sendo abortada pela ditadura militar e substituída por modelos norte-americanos, típico de países dominados, atrasados e dependentes.

Iniciando por Portugal, passando pela França, pela Inglaterra e pelos Estados Unidos, cada um por seu turno, se não impuseram sua forma e seus métodos de formação e educação, pelo menos influenciaram decisivamente. Mais recentemente, sobretudo a partir de 1930, quando os EUA assumiu a hegemonia política e econômica mundial, não só fez do Brasil, como também da América Latina, uma espécie de seu quintal, como também impôs sua cultura, seus valores e seus métodos educacionais.

Na relação com a sociedade global, não há dúvida de que a adoção de um modelo de educação estrangeiro, estranho e alheio à realidade, representa a negação de um modelo próprio e a ausência de identidade própria; representa a alienação e o domínio cultural e material. Contudo, não se trata propriamente de discutir, pura e simplesmente, se se deve ou não ter um projeto de educação e de formação de professores genuinamente nacional. Caso defendamos isso, facilmente derivaremos na discussão se temos que ter um projeto 
estadual e municipal de educação e até mesmo na defesa de uma educação para cada segmento social, como por exemplo, para os sem terra ou uma pedagogia do campo, uma pedagogia para os indígenas, outra para os negros, uma para os da cidade, outra para os da periferia.

Diante da massificação do mercado e do capital que engole tudo e a todos, que procura unificar o mundo à imagem e semelhança da burguesia, até se justifica a tendência é construir formas de resistência, de preservar as micro culturas ou culturas locais ou de segmentos específicos. Isto, porém, cria uma série de problemas. Dentre eles, mencionamos o fato de se correr o risco de legitimar as particularidades, como se tivessem vida própria, isoladas e independentes, em detrimento da totalidade e da universalidade; de perdermos a possibilidade de garantir a unidade e a identidade coletivas; de não reconhecer no particular a expressão da universalidade; de justificar o saber popular compreendido como educação para pobres, de rebaixamento da cultura; de não possibilitar o acesso ao conjunto da cultura historicamente acumulada, enfim, de, por meio da educação, legitimar a atual configuração da sociedade existente.

Todavia, a superação de um modo de produção que intenta globalizar-se e dominar a totalidade, não se dá via redução e fechamento na particularidade, na pequenez, mas sim na incorporação da parte no todo e na construção de um outro modo de produção também universalizante e totalizante. Não se trata apenas de substituir um modo por outro, mas sim de produzir outro que supere e negue as contradições e os antagonismos presentes no atual modo de organização e produção societal.

Claro está que, por questões históricas, geográficas, políticas e culturais a educação não só adquire como deve contemplar contornos nacional, estadual, municipal e que até mesmo deve respeitar as questões locais e de grupos, raças ou povos em que a escola está localizada. Mas é absurdo pensar numa educação para um país, para um estado, município ou para um segmento social. A questão então, também não é se se deve adotar um modelo de formação de professores próprio ou importado, mas sim pensar numa educação humana, voltada para um tipo de homem, de mundo e de sociedade; numa educação que possibilite o acesso à cultura universal, aos bens decorrentes dela e garanta a emancipação humana.

Da mesma forma, também não se trata de adotar um tipo de educação que privilegie apenas um nível de escolaridade, a Educação Fundamental, por exemplo, em detrimento dos demais, como fez o governo FHC e o ministro Paulo Renato. Isto é uma aberração. Pois, como é que se pode dizer que a prioridade é a Educação Fundamental, se não se pensa no Ensino Médio nem no Superior. Como privilegiar a Educação Fundamental se não se pensa na qualificação e na formação de professores para atuar na Educação Básica. Uma coisa é estabelecer uma política que objetive o acesso e a permanência de todas as crianças em idade própria na escola e outra, muito diferente, é dizer que a prioridade é a Educação Fundamental.

Ao contrário de priorizar um ou outro nível ou modalidade educacional, é necessário elaborar uma política que contemple tanto as particularidades e exigências locais ou de segmentos sociais, quanto a identidade coletiva, a totalidade da cultura já produzida até o momento; contemplar todos os seus níveis e modalidades. Além disso, é necessário pensar na articulação entre eles e na relação com a sociedade; compreender a escola como inserida no contexto social e pensar no tipo de organização e funcionamento da sociedade, bem como, no papel e na importância da escola para a sociedade e para a preservação da cultura historicamente acumulada.

Todavia, quando se fala da formação de professores, em geral, a preocupação recai sobre a forma, mais do que sobre os fundamentos e conteúdos ou se privilegia aspectos isolados. Outras vezes, a insatisfação tem ficado no simples descontentamento e 
reclamação dos professores, o que é importante, mas insuficiente. Noutras ainda, foge-se pela tangente e se diz que estamos vivendo num momento de mudanças profundas, num momento de transição e, portanto, que exige professores de outro tipo, dinâmicos, criativos, que sejam capazes de prender a atenção dos alunos, com outra formação, que tenham habilidades, saibam resolver problemas, enfim, estejam preparados para um mundo que muda rapidamente.

Mas, perguntamos: quando é que o mundo não passou por mudanças, quando é que a sociedade não passa por transformações? Veja-se que as questões acima mais deslocam o problema e tergiversam do que permitem enfrentá-lo de fato, pois, ao invés de possibilitar a realização de um diagnóstico de como e porque a formação está da forma como está, e, portanto, permitir a intervenção nela e transformá-la, fica-se fazendo joguinho com palavras e frases de efeito ou de impacto. Em outros termos, fica-se no plano das idéias.

Desde que surgiu a propriedade privada dos meios de produção, também surgiu a divisão do conhecimento. Contudo, é a partir da modernidade, com o advento do positivismo, que o conhecimento e as ciências, por um lado, e o trabalho na indústria, por outro, fragmentaram-se ainda mais. Deste modo, a organização do conhecimento e, consequentemente, a formação também expressam essa fragmentação.

Aristóteles, na antiguidade, expressando a divisão social à época, dizia que os que trabalham não necessitam pensar e os que pensam não necessitam trabalhar. Segundo o autor, a natureza fez os homens assim e a maior perfeição de cada um encontrava-se em cumprir mais e melhor os desígnios que a própria natureza determinou. Com isso, produziu-se a legitimação teórica da divisão prática que vigorava entre os que trabalham e os que pensam.

Todavia, como dissemos, esta divisão se amplia com modo de produção capitalista, que por essência, é fragmentado e exige que essa divisão se aprofunde cada vez mais. Então, se no âmbito da produção, vemos o trabalho cada vez mais parcializado, especializado e fragmentado, de tal forma que os trabalhadores dominam cada vez menos o processo de produção, limitando-se a saber apenas uma pequena parte dele, no campo do conhecimento e da educação, isto não será muito diferente, pois, tende a refletir a fragmentação do mundo material. A divisão do conhecimento que tem na disciplinaridade e nas sua diferentes manifestações, quer seja na multi, na inter ou na transdisciplinaridade e na especialização expressam isso.

Noutras palavras, pode-se dizer que a fragmentação do conhecimento e o tipo de formação do educador, grosso modo, não é fruto da vontade ou mesmo da má vontade dos docentes, estudantes e pesquisadores, mas sim da própria lógica de funcionamento do sistema vigente. Neste sentido, Karl Marx nos diz que, "na produção social da sua vida, os homens contraem determinadas relações necessárias e independentes de sua vontade, relações de produção que correspondem a uma determinada fase de desenvolvimento das forças produtivas materiais" $" 10$.

Isto, por um lado, significa que são os homens que fazem a história ${ }^{11}$, mas não a fazem sob as circunstâncias de sua escolha, nem do jeito e da forma como querem ou que gostariam, mas sim nas condições que encontram e, por outro então, que, para superar a fragmentação do conhecimento e da própria formação, não é suficiente fazer um rearranjo no plano das ideias, como é o caso da inter, da trans ou da multidisciplinaridade. Pressupõe, isto sim, a superação do modo de produção vigente, a negação daquilo que põe, provoca e produz a fragmentação. Entretanto, como destaca Karl Marx, nenhuma filosofia é superada sem que sejam superadas as condições que a produziram ${ }^{12} \mathrm{e}$, indo além, afirma que não serão superados se também não se criarem as condições necessárias para tal. 
Como vimos, na modernidade, com o advento do capitalismo, do liberalismo e do positivismo, a fragmentação do conhecimento, que já existia, aprofunda-se ainda mais, de tal modo que, no plano da organização didática, cognitiva e científica, surgem os mais variados, específicos e diversos campos, ramos, ciências, disciplinas ou áreas do conhecimento. Assim, por exemplo, a história, a filosofia, a política e, poderíamos acrescentar, a sociologia, a psicologia, a antropologia... e outras áreas do conhecimento, muitas vezes, não só são separadas umas das outras como se fossem campos isolados, dissociados e independentes, como são deixadas de lado quando se trata da formação do educador.

Durante o modo de produção primitivo, quando havia apenas a divisão simples do trabalho, fundamentalmente, baseado no gênero macho e fêmea; enquanto não existia a propriedade privada dos meios de produção, dize-se que o conhecimento era realizado por intermédio da vida, era sinônimo de vida. Isto é, os hominídeos educavam-se pela e nas relações sociais, pelo exemplo, pela experiência dos mais velhos e haveis. A socialização do conhecimento e o desenvolvimento coletivo era a garantia de sobrevivência da espécie, tanto de enfrentamento coletivo das ameaças dos demais animais, como das intempéries do tempo e das demais adversidades do meio.

A partir do aperfeiçoamento dos instrumentos, dos conhecimentos e com a mudança no modo de produção da vida material, até mesmo a fillosofia, que desde a antiguidade até na Idade Média era sinônimo de $o$ conhecimento, que reunia praticamente a totalidade do saber da época, a partir daí confunde-se com a Teologia, aparece como sua serva, ou então, confunde-se como se fosse quase que uma coisa só, porém, jamais como independente dela. Entretanto, depois da modernidade, não só adquire independência da teologia, como também das demais disciplinas ou áreas do conhecimento e cada uma delas passa a seguir seu caminho como se nada tivesse a ver com as demais áreas. Ou seja, até mesmo a Filosofia que, de certa forma, antes integrava a totalidade dos conhecimentos, na modernidade perde esse estatuto integrador e passa a ser apenas mais uma disciplina como as demais.

No passado, na antiguidade clássica, assim como ocorria na divisão social do trabalho, em que a ciência e a técnica ainda não eram tanto desenvolvidas quanto no atual momento, em função da etapa de desenvolvimento, a divisão social também era bastante simples, praticamente limitava-se à divisão da sociedade entre os que pensavam e os que trabalhavam. Deste modo, a organização do conhecimento, também expressava essa realidade. Ou seja, o conhecimento também era pouco dividido, fragmentado.

A divisão social aparecia ou se expressava no plano do pensamento como Filosofia, que é a primeira forma de organização do conhecimento, que supera a mitologia, mas permanece privilégio dos cidadãos, dos proprietários à época. Pensando na totalidade social, pode-se dizer que a sociedade antiga estava dividida entre os que pensavam e os que trabalhavam, ou então, a filosofia era o "trabalho dos que não trabalhavam", isto é, da aristocracia, dos cidadãos, dos proprietários, dos donos dos meios de produção e que, portanto, viviam no ócio, uma vez que tinham quem trabalhava para eles, os escravos, que produziam e garantiam a sobrevivência dos que não trabalhavam e, que, deste modo, podiam se dedicar à filosofia.

Nessa condição, a Filosofia reunia e englobava todo conhecimento da época. Não havia divisão entre as diferentes áreas ou disciplinas. Tanto é que, filósofo, etimologicamente falando, significa amigo do saber, justamente porque se dizia que ele detinha todos os conhecimentos existentes. Assim, congregava tanto os conhecimentos da física, da matemática, da química, da aritmética, como da astronomia, da psicologia, ou 
seja, reunia todo o conhecimento existente. Todavia, a partir da modernidade a filosofia passa a ser apenas mais um ramo do conhecimento ou mais um dentre muitos outros.

Com isso, queremos dizer que não podemos pensar nem no conhecimento e em sua organização, nem na formação de professores em si, como se tivessem vida própria. Precisamos pensá-los e compreendê-los como expressão da sociedade da época e do modo como se organiza para produzir sua existência, bem como, da etapa de desenvolvimento das forças produtivas materiais. Noutras palavras, por um lado, significa que a fragmentação que enfrentamos neste momento, é expressão da sociedade capitalista e do grau de desenvolvimento atingido e, por outro, que a superação do atual estado de coisas, só ocorrerá efetivamente com a superação do modo de produção que produz esta fragmentação.

Isto significa que se hoje temos uma sociedade profundamente fragmentada, então a educação não é mais para a vida como era nas comunidades primitivas? De fato a sociedade passou por um longo e profundo processo de transformação. Se a sociedade não é mais a mesma, a educação também não é mais feita da mesma forma e nas mesmas condições.

Alguns intelectuais defendem que se a sociedade mudou, então, hoje não temos mais uma educação para e pela vida. Contrariando estas posições, pode-se afirmar que, mesmo assim, o caráter e a finalidade da educação não mudaram. A educação continua sendo para e pela vida, mas para a vida na atual sociedade, é óbvio, como não poderia deixar de ser.

Não podemos pensar que a sociedade mude, mas querer que a educação continue sendo para a vida como ocorria na sociedade antiga. Temos que pensar que a educação corresponde à sociedade de cada época e, portanto, a educação de hoje corresponde à forma de organização e reprodução da sociedade e do modo de produção do atual momento. Ou seja, a educação continua sendo para a vida, porém, para a vida na sociedade capitalista.

No caso da formação do educador, precisamos reconhecer que educação não é sinônimo de escola, de educação formal. Existem muitas formas e meios de se educar os indivíduos. A família, a rua, o trânsito, as instituições, o trabalho educa, de tal modo que podemos falar em educações, no plural. Assim, a escola aparece apenas como mais uma das formas ou dos meios pelos quais a sociedade se utiliza para educar os indivíduos. Então, em que consiste a educação? Num conceito um tanto amplo, pode-se afirmar que "a educação é a forma como a sociedade se utiliza para educar os indivíduos para viverem nela mesma"13. Marx, à seu modo afirma que

A doutrina materialista da transformação das circunstância e da educação
esquece que as circunstâncias têm de ser transformadas pelos homens e
que o próprio educador tem de ser educado. (...) A coincidência da
mudança das circunstâncias e da atividade humana ou autotransformação
só pode ser tomada e racionalmente entendida como práxis
revolucionária ${ }^{14}$.

Isto reforça a tese de que a educação não se limita à escola, de que quem educa o homem não é apenas um outro homem, um professor, mas sim a sociedade, que educa tanto pelo que faz, como pelas condições em que vive. Além disso, é ela que dita seus fins, sua forma, estabelece sua extensão, sua qualidade, sua quantidade, que define a quem e como ela será distribuída.

Como diria Álvaro Vieira Pinto, deslocar o professor, a educação ou a formação de professores da totalidade das relações, à moda positivista, e pensar na educação como se 
ela se restringisse às quatro paredes da escola, à educação formal ou achar que o educador é apenas um indivíduo, um professor, expressa uma concepção ingênua de educação e de sociedade, pois, desconsidera as inúmeras variáveis, fatores e relações sócio-históricas que incidem sobre ela ${ }^{15}$.

Ao contrário disso, pode-se dizer que em cada sociedade e em cada época temos um tipo de educação, tanto no sentido amplo, quanto de escola, e que este tipo não é aleatório, nem fortuito, mas que corresponde à etapa de desenvolvimento da época e da sociedade, ao nível de consciência e das exigências sociais, bem como, ao grau de acirramento dos conflitos e das lutas travadas na sociedade. Posto isso, também se depreende que ela vai mudando e se transformando à medida que a sociedade vai sendo transformada.

Esta compreensão é significativa porque parte de uma concepção de totalidade, que envolve a sociedade e a educação no seu todo e, portanto, de contradição e, simultaneamente, também elimina o caráter quase que absoluto, mítico e até mesmo redentor da escola.

Todavia temos que admitir que a discussão em torno da educação, do professor e até mesmo da formação de professores, geralmente tem sido feita a partir de um enfoque positivista e reducionista. Desse modo, a educação aparece como se fosse apenas sinônimo de escola e, deslocando-a do conjunto das relações sociais, por um lado, tem se atribuído a ela um caráter redentor e revolucionário ou, por outro, contrariamente a isto, tem se esvaziado seu papel, sua importância e suas possibilidades.

Na perspectiva positivista, a formação de professores tem se resumido à preparação técnica. Não é por acaso que, na formação de professores, em geral, eles se mostram avessos a qualquer reflexão e discussão teórica acerca da relação entre educação e sociedade, acerca dos fundamentos, dos pressupostos históricos, políticos, filosóficos e sociais que embasam a atividade educativa e querem que somente se ensine "como fazer", que se exercite habilidades e competências. Dizem: quero saber como se faz isso na prática... Assim, caem reféns da própria concepção. Pois, como saber fazer se não se tem conhecimento teórico, se não se conhece a história, a política a sociedade? Sem teoria, não há prática. No máximo a que se pode chegar é no espontaneísmo, no praticismo, no ir fazendo de acordo com a experiência adquirida.

Aqui também poderíamos dizer que se entende o fato de os professores mostraremse avessos às discussões teóricas. Fica difícil pensar em como estudar, ler, pesquisar e refletir se as precárias condições de trabalho, os baixos salários e a sobrecarga cotidiana acabam por exigir, sugar e ocupar a vida como um todo. Nestas condições, o tempo dedicado à teoria e ao estudo pode parecer que deixam menos tempo ainda para fazer o trabalho e seja um outro fator de pressão sobre o professor. Todavia, ele acaba apenas por preocupar-se com o prático, com o que e como fazer. Dessa forma, entra-se num ciclo vicioso. Por um lado, enquanto não reflete e não conhece, não consegue tomar consciência do porque encontra-se nesta condição e de que a situação poderia ser diferente e, por outro, enquanto está subsumido ao trabalho não tem tempo para pesquisar, refletir e compreender melhor a prática e se organizar e lutar contra as condições a que encontra-se submetido e, sobrecarregado, resta apenas o ir fazendo. Dessa forma, mostra-se avesso não só à teoria como também a qualquer mudança que desestabilize.

Poderíamos aqui tomar o caso da discussão que ocorre em torno da prioridade ao ensino da língua portuguesa e da matemática. Devido a problemas teóricos, alguns intelectuais e docentes defendem a tese de que se os alunos sabem ler e se sabem matemática, consequentemente, também saberão história, geografia e as demais disciplinas. Com isso tentam justificar maior carga horária destinada a estas disciplinas. 
Mas, perguntamos: que análise e interpretação de texto, por exemplo, alguém consegue fazer sem ter conhecimentos, sem informações, sem conhecer a história, a filosofia, a política, a sociologia? Vemos, portanto, que este é um discurso fácil, porém, oco e vazio. Em consequência, não se pensa seriamente na organização curricular e na própria educação. Então, vemos que os alunos não estão sabendo nem história, nem filosofia, sociologia, ciências, língua portuguesa, nem matemática, apesar de maior cargo horária destinada a estas duas disciplinas. Ou seja, é uma falácia defender pura e simplesmente o modelo tradicional de organização curricular. É preciso repensar toda a escola.

Uma vez que a educação tem a ver com a totalidade social, deslocá-la dessas relações, transformá-la numa espécie de mito e exigir que dê conta dessa totalidade, é o mesmo que assumir ou decretar que os professores são incapazes, incompetentes e que a escola é ineficiente.

Por isso, como nos diria novamente Álvaro Vieira Pinto,

Qualquer que seja o campo de atividade a que o trabalhador científico se aplique, a reflexão sobre o trabalho que executa, os fundamentos existenciais, os suportes sociais e as finalidades culturais que o explicam, [...] não podem ficar à parte do campo de interesse do pesquisador ${ }^{16}$.

O intelectual, em especial o educador, não pode fazer seu trabalho de qualquer modo, nem apenas amparar-se na própria experiência acumulada ao longo dos anos. Deve, isto sim, preocupar-se tanto com os fundamentos históricos, filosóficos, psicológicos, legais, políticos e culturais, quanto com as implicações sociais do trabalho que realiza.

Pois, como diria Charles A. Beard, (s/d), caso nos descuidemos disso, podemos correr o risco de, por um lado, expulsar do espírito ostensivamente pela porta principal a grande filosofia, mas por outro, deixar que os preconceitos tacanhos de classe e do meio entrem pela porta dos fundos, estendendo seu domínio sobre o pensamento e a prática do educador.

Neste sentido, partindo de uma concepção de totalidade, entendendo que a educação e a formação de professores tem a ver com o conjunto das relações, é necessário transformar a educação não numa responsabilidade exclusiva do professor, mas sim numa responsabilidade social. Deste modo, já que a educação tem a ver com a totalidade social, ao invés de o professor ser visto como o único responsável pela forma como ela se encontra, ele divide esta responsabilidade com a sociedade, que é efetivamente a grande educadora. Educação não é só ensinar conhecimentos em sala de aula. A construção de um outro tipo de educação, vai depender da sociedade, inclusive do professor, que faz parte dela, bem como, do investimento que se faz, do nível de consciência, da exigência que tem, da importância que atribui a ela.

Se a partir da modernidade, com o advento do liberalismo e do positivismo, a realidade aparece cada vez mais cindida, se cada uma das dimensões do conhecimento ou áreas do saber passa a ser concebida como um campo ou disciplina isolada e independente das demais, se o conhecimento passa a ser visto como estanque, a formação do educador também deixa de ter uma preocupação com a totalidade e tende a se fragmentar, refletindo a cisão presente na materialidade. Diante disso, vemos que a formação do educador também é empobrecida, ficando praticamente restrita às áreas do conhecimento específico a que o estudante pretende se profissionalizar. Nessas condições, não só as dimensões históricas e filosóficas desapareceram dos currículos, como também a política? Nos documentos oficiais nem mais se fala em Projeto Político Pedagógico - PPP -, no máximo fala-se em Projeto Pedagógico Escolar - PPE -, quando não apenas em currículo, retirando-se ou esvaziando-se a dimensão política. 
O fato, porém, de que a organização do conhecimento apareça ou seja representada de forma cindida, disciplinar, em áreas estanques, não significa que na realidade concreta também seja assim. Podemos falar que a realidade é una e íntegra, que nela não existe propriamente divisão, uma área de matemática, outra de história, outra de política, outra de cultura, outra de filosofia, outra de ciências, outra de língua portuguesa e assim por diante. Na verdade o conhecimento é uma unidade, uma totalidade, assim como a vida. Sua representação, porém, é que tem sido feita de forma fragmentada expressando a divisão social em classes.

Se nos utilizarmos, por exemplo, da idéia de um retrovisor, poderíamos dizer que o conhecimento se confunde com o próprio homem, com sua história, com seu processo de ação, com a sua compreensão, com seu desenvolvimento e com as transformações ocorridos ao longo do tempo. Nesse processo encontram-se integrados todos os conhecimentos, todas as técnicas e habilidades humanas, que sendo apropriadas, acumuladas e instrumentalizadas pelo próprio homem ajudam a resolver os desafios que lhe foram colocados ou que produziu.

Contudo, da forma como organizamos hoje o conhecimento, se quisermos utilizá-lo para "olhar" para o passado, perceberemos que, ao invés de possibilitar a compreensão do homem, da história, do processo de transformação e da própria sociedade no seu todo, ele contribui para realimentar a fragmentação e a própria sociedade de classes no plano do pensamento e, portanto, para perpetuar a alienação e a divisão social.

Ao contrário disso, então, parafraseando o que nos fala Marx na $11^{\mathrm{a}}$ Tese sobre Feuerbach, devemos fazer do conhecimento não apenas mais uma forma de representação e interpretação de mundo, de homem e sociedade de modo diferente, mas sim fazer dele um meio de transformação, ou seja, devemos organizar o conhecimento e formar educadores de tal modo que possibilite dominar e se apropriar da história, do homem e da sociedade, que possibilite conhecer a própria educação e sua história, que possibilite recuperar o passado, compreender o presente, superar as contradições antagônicas e transformar o futuro.

Aqui então, podemos parafrasear novamente Marx quando chama atenção de que "a crítica do céu se converte na crítica da terra"17, ou seja, ao invés de tomarmos o conhecimento como estanque, neutro, dissociado da realidade; ao invés de as ideias serem compreendidas como meros enfeites do cérebro, devem ser compreendidas como instrumentos fundamentais e indispensáveis para se apropriar da realidade, para fazer o inventário dela e, uma vez feito isso, possibilitar uma ação transformadora.

Entretanto, se, a realidade é fragmentada, se o saber aparece dividido, se a formação do educador não contempla uma concepção de unidade, integradora e de totalidade e se estabelecemos relações necessárias e independentes de nossa vontade, relações que correspondem à etapa de desenvolvimento das forças produtivas materiais e das relações de produção, ao modo de produção da época, se as condições de vida e de trabalho não são as melhores, então significa que a formação também é deficitária por que corresponde a este modo de produção.

Então, não há saída? Não. Penso que estamos no momento mais adequado que já existiu historicamente e que de fato permite a superação do estado de coisas em que nos encontramos. Já desenvolvemos uma capacidade racional altamente desenvolvida, bem como, conhecimentos científicos que permitem se apropriar e dominar a realidade prática e a história no plano do pensamento. Assim, hoje, já temos condições de manipular idealmente a realidade, de romper com a ditadura da natureza e da matéria, de nos distanciar dela, de projetar o que pretendemos, de intervir efetivamente e construir uma 
nova realidade, superando a fragmentação e recuperando a unidade do ser humano, desenvolvendo todas as suas potencialidades e emancipando-o humanamente.

Iniciamos nossa fala dizendo que, apesar do tema central desta discussão ser a formação do educador e que, para compreendê-la devidamente, ao invés de ir diretamente a ela, é preciso nos distanciar um pouco e trazer para a discussão elementos para além dela. Agora, ao finalizá-la dizemos que a problemática da formação do educador não será superada se não for uma exigência social ${ }^{18}$.

Porém, como afirma Karl Marx,

As armas da crítica não podem, de fato, substituir a crítica das armas; a força material tem de ser deposta por força material, mas a teoria se converte em força material uma vez que se apossa dos homens. A teoria é capaz de prender os homens desde que demonstre sua verdade face ao homem, desde que se torne radical $^{19}$.

Por meio desta citação de Marx recuperamos novamente a questão da relação teoria e prática. Por um lado, ela expressa que a teoria, a crítica não é suficiente, que a questão se resolve de fato na prática e, por outro, que a crítica e a teoria são necessárias e indispensáveis para a superação prática do problema. Quando a teoria se apossa das massas, quando for expressão da necessidade social, não há dúvidas de que ela revoluciona e transforma a realidade. Quando os trabalhadores se reconhecerem enquanto classe, quando ao invés de viverem à míngua do conhecimento e dos bens materiais, quando perceberem que se produzem, também podem usufruir deles e ter uma vida realmente digna, não há dúvida de que farão a revolução. Para isso, de fato, necessitam conquistar sua identidade de classe. Nesse sentido, como nos diz Marx, a filosofia encontra no proletariado suas armas materiais e o proletariado encontra na filosofia suas armas espirituais $^{20}$. Para isso, a formação do educador deve necessariamente contemplar os aspectos históricos, filosóficos, políticos e culturais de forma indissociada, permitindo compreender o homem, sua história, bem como transformá-los.

Para concluir trago novamente uma citação de Álvaro Vieira Pinto que me parece muito significativa. Para ele:

[...] libertar-se política, econômica e culturalmente das peias do atraso e da servidão, a apropriação da ciência, a possibilidade de fazê-la não apenas em si, mas para si, é condição vital para a superação da etapa da cultura reflexa, vegetativa, emprestada, imitativa, e a entrada em nova fase histórica [...]. A ciência só pode tornar-se um instrumento de libertação do homem e do seu mundo [...] se for compreendida por uma teoria filosófica ${ }^{21}$.

A reflexão sobre a formação de professores, para além das fórmulas e receitas prontas; para além das saídas de tipo novidadeiras ou pós-modernas, da formação para um mundo em mudança, da formação para o século XXI ou para as competências, precisa considerar a totalidade social, compreender o modo de organização da sociedade e fazer da educação um espaço de apropriação do conhecimento e da cultura historicamente acumulada, o que equivale a dizer, do próprio homem; um espaço de reflexão sobre a realidade existente, que incorpore fundamentalmente as perspectivas históricas, políticas e filosóficas, e que permita realizar uma ação efetivamente transformadora. 


\section{Bibliografia}

Bíblia Sagrada. São Paulo: 26a Ed., 1979.

MARX, K. Para a crítica de economia política. In: . Manuscritos Econômicos e Filosóficos e outros textos escolhidos. $5^{\text {a }}$ Ed., São Paulo: Nova Cultural, 1991, p. 17. (Os Pensadores). Seleção de textos de José Arthur Giannotti e tradução de José Carlos Bruni. [et al.].

. Prefácio à "contribuição à Crítica de Economia Política". In: MARX, K. e ENGELS, F. Obras Escolhidas. São Paulo: Alfa-Omega, s/d.

. O 18 Brumário de Louis Bonaparte, 1987.

. Introdução à crítica da filosofia do Direito de Hegel. In: A questão judaica. $5^{\mathrm{a}}$ Ed., São Paulo: Centauro, 2000.

. Teses sobre Feuerbach. In: MARX, K e ENGESL, F. Ideologia Alemã. Lisboa: Avante, 1981

ORSO, Paulino José. Educação na sociedade de classes: possibilidades e limites. In: ORSO, P. J., GONÇALVES, S. R. e MATTOS, V. M. Educação e Lutas de Classes. São Paulo: Expressão popular, 2008.

PINTO, Álvaro Vieira. Sete lições sobre educação de adultos. $9^{\mathrm{a}}$ edição, São Paulo: Cortez editora, 1994.

Ciência e Existência: problemas filosóficos da pesquisa científica. Rio de janeiro: Paz e Terra, 1979.

Notas:

\footnotetext{
${ }^{1}$ Doutor em História e Filosofia da Educação pela Unicamp, docente do Curso de Pedagogia e do Mestrado em Educação da Unioeste, Campus de Cascavel e líder do Grupo de Pesquisa em História, Sociedade e Educação no Brasil - GT da Região Oeste do Paraná - HISTEDOPR.

${ }^{2} \mathrm{Na}$ ausência de um Projeto Político Pedagógico articulador, que envolva o conjunto dos profissionais da escola, que integre e unifique todos os projetos e ações nela desenvolvidas, resta a cada um faz o seu projetinho, seguir o seu caminho, do seu jeito e fazer o trabalho do jeito que entende, noutras palavras, significa que a escola não tem direção, não tem referência, não sabe de onde veio, onde e em que condições se encontra, nem para onde pretende ir.

${ }^{3}$ Cf. MARX, K. Para a crítica de economia política. In: . Manuscritos Econômicos e Filosóficos e outros textos escolhidos. $5^{\text {a }}$ edição, São Paulo: Nova Cultural, 1991, p. 17. (Os Pensadores). Seleção de textos de José Arthur Giannotti e tradução de José Carlos Bruni. [et al.].

${ }^{4}$ Bíblia Sagrada. São Paulo: 26 edição, Gêneses, 1979. Gen 1, 1-31.

${ }^{5}$ Idem. Evangelho de São João. Jo 1, 1 e 14.

${ }^{6}$ Se não bastasse isso, mistificam-se os próprios conceitos de idealismo e materialismo. Se reduz o idealismo a um mero sonho, um ideal e o materialismo ao apego aos bens materiais, ao dinheiro e não uma concepção de mundo. Esvaziam-se os conceitos, para também esvaziar e mistificar o conteúdo, favorecendo as ideias em detrimento da materialidade. Quando, na realidade ocorre exatamente o inverso, pois, a primazia está na prática, na realidade concreta sobre as idéias e o pensamento.
}

${ }^{7}$ MARX, K. Para a crítica de economia política. In: __ . Manuscritos Econômicos e Filosóficos e outros textos escolhidos. $5^{\text {a }}$ edição, São Paulo: Nova Cultural, 1991, p. 17. (Os Pensadores). Seleção de textos de José Arthur Giannotti e tradução de José Carlos Bruni. [et al.].

${ }^{8} \mathrm{O}$ mesmo se poderia dizer em relação à forma e ao conteúdo ou a causa e ao efeito. Uma não existe sem o outro, são interdependentes e indissociados. Assim, num dado momento do processo, ambos aparecem como 
simultaneamente como idênticos, um é aparece como sendo o outro, a causa o efeito e o efeito causa, o conteúdo a forma e a forma o conteúdo.

${ }^{9}$ MARX, K. Prefácio à “contribuição à Crítica de Economia Política”. In: MARX, K. e ENGELS, F. Obras Escolhidas. São Paulo: Alfa-Omega, s/d. p. 301.

${ }^{10}$ Idem, p. 301.

${ }^{11}$ Cf. MARX, Karl. O 18 Brumário de Louis Bonaparte, 1987, p.15.

${ }^{12} \mathrm{Cf}$. MARX, K. Introdução à crítica da filosofia do Direito de Hegel. In: . A questão judaica. $5^{\mathrm{a}}$ edição, São Paulo: Centauro, 2000, p. 92-102.

13 ORSO, Paulino José. Educação na sociedade de classes: possibilidades e limites. In: ORSO, P. J., GONÇALVES, S. R. e MATTOS, V. M. Educação e Lutas de Classes. São Paulo: Expressão popular, 2008, p. 50 .

${ }^{14}$ MARX, K. Teses sobre Feuerbach. In: MARX, K e ENGESL, F. Ideologia Alemã. Lisboa: Avante, 1981, p. 104

${ }^{15}$ Cf. PINTO, Álvaro Vieira. Sete lições sobre educação de adultos. 9a edição, São Paulo: Cortez editora, 1994.

${ }^{16}$ PINTO, Álvaro V. Ciência e Existência: problemas filosóficos da pesquisa científica. Rio de janeiro: Paz e Terra, 1979, p. 3.

${ }^{17}$ MARX, K. Introdução à Crítica da Filosofia do Direito de Hegel. In: Questão Judaica. São Paulo: Centauro, 2000, p. 86.

${ }^{18}$ Idem, p. 95.

${ }^{19}$ Idem, p. 94.

${ }^{20}$ Idem, p. 101.

${ }^{21}$ PINTO, Álvaro Vieira. Ciência e Existência. Rio de Janeiro: Paz e Terra, 1979, p. 4.

Recebido em: $\quad$ 15/10/10

Aprovado em: 10/11/10 